\title{
Paired $\Delta_{47}$ and $\Delta_{48}$ carbonate clumped isotope data: Standard values, multi- instrument comparisons, mixing effects, and disequilibrium effects
}

\author{
JAMIE K LUCARELLI ${ }^{1}$, HANNAH M. CARROLL ${ }^{1}$, \\ BETTINA PURGSTALLER ${ }^{2}$, MARTIN DIETZEL ${ }^{3}$, ROBERT \\ A EAGLE $^{1}$ AND ARADHNA TRIPATI ${ }^{4}$ \\ ${ }^{1}$ University of California, Los Angeles \\ ${ }^{2}$ Institute of Applied Geosciences \\ ${ }^{3}$ Graz University of Technology \\ ${ }^{4}$ University Brest \\ Presenting Author: jklucarelli@gmail.com
}

The clumped isotope $\left(\Delta_{47}\right)$ thermometer is a proxy that is growing in use throughout many areas of geosciences, including paleoclimate reconstructions of air and ocean temperatures, paleo-physiology, and paleoelevation. Recent work has demonstrated that isotopic disequilibrium may affect the accuracy of $\Delta_{47}$-based reconstructions, and coupled $\Delta_{47}-\Delta_{48}$ analysis may shed light on the origin of kinetic effects and increase confidence in temperature estimates from carbonate minerals (Hill et al., 2014; Tripati et al., 2015; Fiebig et al., 2019; Bajnai et al., 2020). Due to the extremely low abundance of mass $48 \mathrm{CO}_{2}$ isotopologues, the development of robust standard values for $\Delta_{48}$ is critical to ensure accurate determination of unknown sample $\Delta_{48}$ values. Here we take advantage of newly developed analytical capabilities for the measurement of the primary mass $48 \mathrm{CO}_{2}$ isotopologue $\left({ }^{12} \mathrm{C}^{18} \mathrm{O}^{18} \mathrm{O}\right)$ and report carbonate standard values determined against equilibrated gases over a three-year interval for 8 standards $(n=425)$, which lays the foundation for accurate determination of $\Delta_{47}-\Delta_{48}$ values on an absolute reference frame using both equilibrated gas and carbonate standard-based standardization. Further, we demonstrate that the application of carbonate standardization yields reproducible $\Delta_{47}-\Delta_{48}$ measurements for $>12$ standards on three instrument configurations using standard data collected over a five-year interval $(\mathrm{n}=4164)$. We report mixing experiment data and nonlinear mixing model calculations for $\Delta_{48}$ and $\Delta_{47}$ vs $\Delta_{48}$ for samples with varying bulk isotope $\left(\delta^{18} \mathrm{O}\right.$ and $\left.\delta^{13} \mathrm{C}\right)$ values. Equilibrium and disequilibrium processes are constrained by comparing $\Delta_{47}-\Delta_{48}$ data for different carbonates, including synthetic calcite, Devil's Hole cave calcite, and field-collected biogenic carbonates. 